A SOLID MEMBRANE ELECTRODE FOR STRONTIUM IONS

S.K. SRIVAS'TAVA ${ }^{\circledR}$ and C.K. JAIN

Department of Chemistry, University of Roorkee Roorkee - 247667 , India

\begin{abstract}
A heterogeneous membrane electrode fabricated with hydrous thorium oxide gel embedded in polystyrene matrix as the sensor material, has been used for the estimation of stron tium ions. The electrode responds to strontium ion in a nearly Nernstian manner over the concentration range $10^{-1}$ to $10^{-4} \mathrm{M}$. It can be used in the $\mathrm{pH}$ range 2.5 to 5.5 as well as in partially non-aqueous system. The membrane electrode shows good selectivity to strotium ions. A membrane treated with cationic surfactant not only becomes immune to detergent interference, but also exhibits a larger validity range. It has also been used as an indicator electrode in potentiometric titrations involving strontium ions.
\end{abstract}

\title{
IN TRO DUCTI ON
}

Ion selective electrodes are suitable sensors for ion activity measurement over a wide concentration range and are practically useful in continuous analysis where constituents show major variations in concentration. Several solid and liquid membrane electrodes for barium ${ }^{1)}$ 2) and strontium ${ }^{3)}$ 4) have been reported in literature but almost all of these have a number of limitations. Some of these have serious interference of $\mathrm{Cs}^{+}, \mathrm{Ba}^{2+}$ and $\mathrm{Hg}^{2+}$ ions.

In continuation to our work on some ion selective electrodes ${ }^{5)}$-8) it is observed that a solid thorium oxide membrane exhibits promising selectivity for strontium ions and the electrochemical performance of this membrane electrode is reported in this paper.

\section{EXPERIMENTAL}

All reagents used were of analytical grade. Hydrous thorium oxide (THO) gel was prepared ${ }^{9)}$ by slow addition of $0.1 \mathrm{M}$ ammonium hydroxide to a well stirred solution of $0.1 \mathrm{M}$ thorium nitrate maintained at $70^{\circ} \mathrm{C}$. The gel was digested for $4 \mathrm{~h}$ at the same temperature to remove any excess of ammonium hydroxide and to allow desorption of trapped ions. It was then filtered off, washed with distilled water and dried at $50^{\circ} \mathrm{C}$.

Preparation of Membranes. Homogeneous membrane of THO could not be prepared. Heterogenous membranes obtained by embedding polystyrene (15\%) in a thorium oxide gel were found to be quite stable and were therefore employed in these investigations. The method used for preparing membranes is the same as reported earlier ${ }^{5}$. 
Potential Measurements. Membranes thus obtained were equilibrated with $0.1 \mathrm{M}$ strontium chloride solution for 3-4 days. The solution was repeatedly changed four to five times during this period. The equilibration time was determined following preliminary investigations and it was observed that membranes equilibrated for shorter periods did not show stable and reproducible potentials.

The electrode assembly used for potential masurements was the same as reported earlier ${ }^{5)}$, the reference solution being $0.1 \mathrm{M}$ strontium chloride in all the runs. Saturated calomel electrodes were used as reference electrodes. Emf measurements were made with a sensitive potentiometer having a resolution of $\pm 0.1 \mathrm{mV}$. All observations were made at $25 \pm 0.1^{\circ} \mathrm{C}$.

\section{RESULTS AND DISCUSSION}

The potentials observed with this membrane in contact with strontium ions $\left(10^{-1}\right.$ to $\left.5 \times 10^{-6} \mathrm{M}\right)$ are shown in Fig. $1(\mathrm{a})$. The response is linear and nearly Nernstian (slope $31.5 \mathrm{mV}$ per decade of concentration) over the concentration range $10^{-1}$ to $10^{-4} \mathrm{M}$.

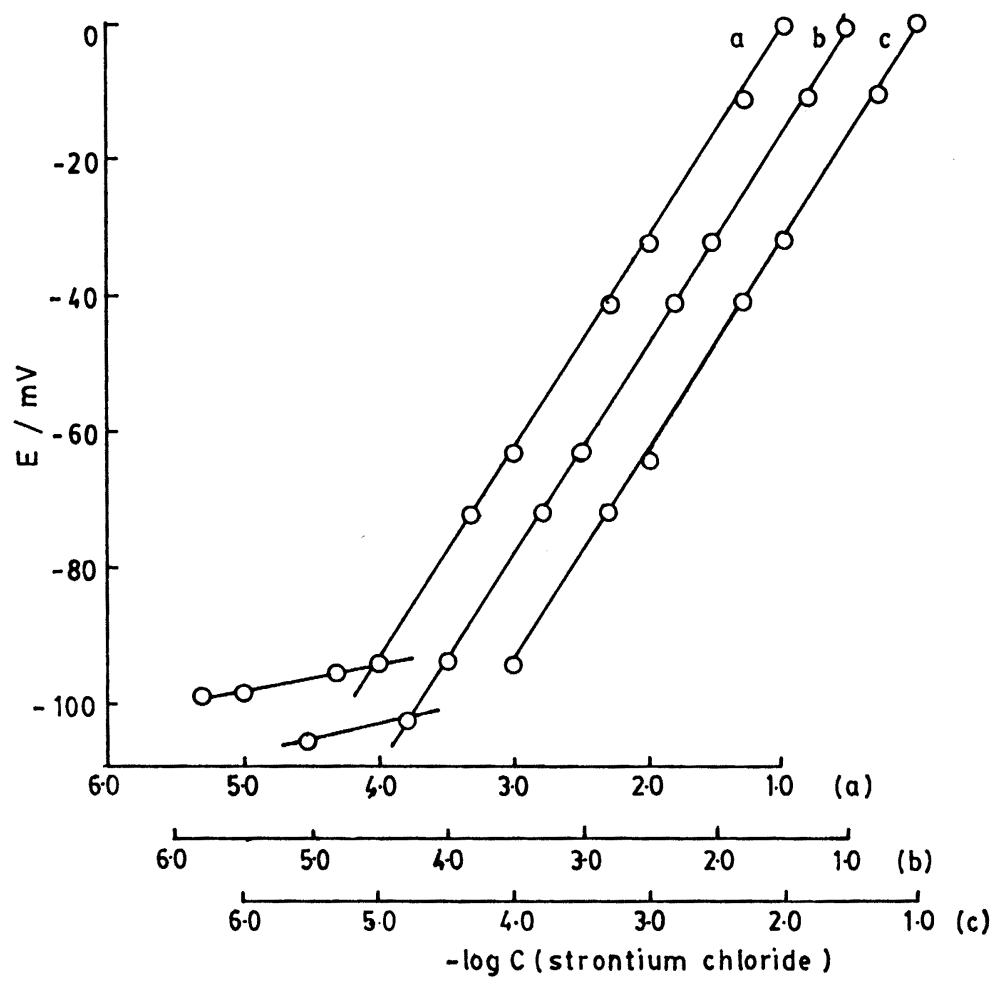

Fig. I Plots of potential vs - log concentration of strontium ions

(a) original membrane; (b) conditioned membrane;

(c) in presence of $10^{-3} \mathrm{M}$ cesium ions. 
In dilute solutions the response of the electrode deviates from linear behaviour and the potential stays constant below a concentration of $10^{-4} \mathrm{M}$. The electrode response is fast, stable potentials being obtained within a few seconds, and no deviations are observed within an hour, after which a slow drift in potential occurs. The response time (static) is found to be 20-30 s. Potentials generated were repeatedly monitored and a standard deviation of $0.3 \mathrm{mV}$ is observed in the functional concentration range of the electrode assembly.. It can be used for six months in a working range of three orders of magnitude of strontium ion activity without showing any drift but it is likely to get contaminated after a long continuous use and the same can be regenerated by equilibration with a fresh strontium chloride solution.

The $\mathrm{pH}$ dependence of the electrode has also been investigated at two different concentrations by additions of $\mathrm{HCl}$ or $\mathrm{NaOH}$ to adjust the $\mathrm{pH}$ of the solution. It is observed that the electrode is tolerant of $\mathrm{pH}$ changes in the range 2.5 to 5.5 (Fig. 2). A change in potentials at low pH may be attributed to the interference of hydrogen ions.

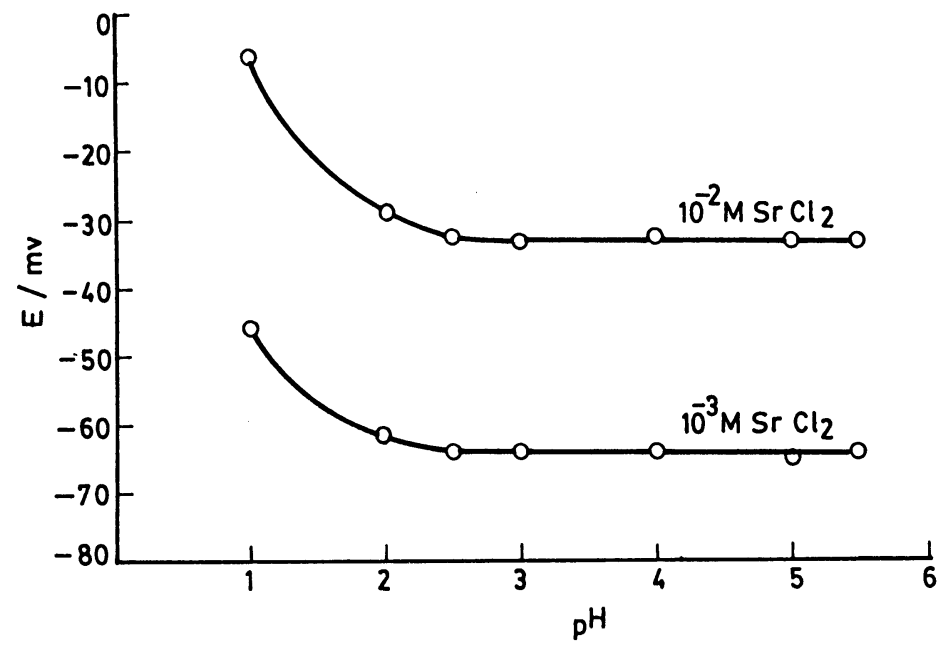

Fig. 2 Plots showing the variation of membrane potential with $\mathrm{pH}$

The electrode assembly can also be used to measure strontium ion concentration in partially non-aque ous media, up to a maximum of $30 \%$ non-aque ous content. If the non-aqueous content is more than 30\% the response time of the electrode rises to 5-6 min and a potential drift also occurs.

The periormance of this electrode has been assessed in presence of other ions and its selectivity for strontium ion over other ions has been determined by fixed interference method ${ }^{10)}$. The selectivity coefficient $\left(k_{A, B}^{P \circ t}\right)$ values are given in Table $l$. 
Table 1 Selectivity coefficient values for hydrous thorium oxide membrane at $10^{-3} \mathrm{M}$ concentration of interfering ions

\begin{tabular}{llll}
\hline Ion & $\mathrm{k}_{\mathrm{A}, \mathrm{B}}^{\text {Pot }}$ & Ion & $\mathrm{Kk}_{\mathrm{A}, \mathrm{B}}^{\text {Pot }}$ \\
\hline $\mathrm{Li}^{+}$ & $9 \cdot 2 \times 10^{-1}$ & $\mathrm{Ba}^{2+}$ & $2.1 \times 10^{-2}$ \\
$\mathrm{Na}^{+}$ & $9.5 \times 10^{-1}$ & $\mathrm{Ca}^{2+}$ & $2.0 \times 10^{-2}$ \\
$\mathrm{~K}^{+}$ & $9.8 \times 10^{-1}$ & $\mathrm{Mg}^{2+}$ & $1.9 \times 10^{-2}$ \\
$\mathrm{NH}_{4}^{+}$ & $9 \cdot 9 \times 10^{-1}$ & $\mathrm{~Pb}^{2+}$ & $1.7 \times 10^{-2}$ \\
$\mathrm{Rb}^{+}$ & $9 \cdot 4 \times 10^{-1}$ & $\mathrm{Cd}^{2+}$ & $1.2 \times 10^{-2}$ \\
$\mathrm{Cs}^{+}$ & $9 \cdot 9 \times 10^{-1}$ & $\mathrm{Co}^{2+}$ & $1.3 \times 10^{-2}$ \\
$\mathrm{TI}^{+}$ & $7 \cdot 9 \times 10^{-1}$ & $\mathrm{Ni}^{2+}$ & $1.4 \times 10^{-2}$ \\
$\mathrm{Mn}^{2+}$ & $2.2 \times 10^{-2}$ & $\mathrm{Al}^{3+}$ & $6.8 \times 10^{-3}$ \\
$\mathrm{Hg}^{2+}$ & $2.1 \times 10^{-2}$ & $\mathrm{Fe}^{3+}$ & $4.9 \times 10^{-3}$ \\
$\mathrm{Zn}^{2+}$ & $2.1 \times 10^{-2}$ & $\mathrm{Cr}^{3+}$ & $6.2 \times 10^{-3}$ \\
\hline
\end{tabular}

It is observed that the bivalent and trivalent cations do not interfere even if present at the same concentration as that of primary ion. Selectivity coefficient values for monovalent ions are 0.9-1.0. Normally a zero value is ideal but the values obtained for univalent cations for this electrode system are negligibly small in comparison to the limiting selectivity coefficient value at which an interfering ion exhibits same response as the primary ion. Thus the proposed electrode assembly is substantially free of interference of $\mathrm{Ba}^{2+}$ or $\mathrm{Hg}^{2+}$ - a drawback reported with other strontium electrodes and the monovalent cations would also not interfere with the working of this electrode system unless their concentration exceeds manyfold with the concentration of the primary ion. This has further been verified by making a mixed run of the primary and a monovalent interfering ion [Fig・ I(c)].

The electrode system is also tolerant of the smaller amount of anionic surfactants (sodium dodecyl sulphate or sodium dodecyl benzene sulphonate). Cationic surfactants (cetyl trimethyl ammonium bromide or cetyl pyridinium bromide), even when present in smaller amounts $\left(10^{-4} \mathrm{M}\right)$ cause appreciable interference, but it is observed that a membrane after treated with a cationic surfactant $\left(10^{-4} \mathrm{M}\right)$ for $24 \mathrm{~h}$ becomes immune to its effect. Table 2 indicates the data observed when $\mathrm{CPB}$ or $\mathrm{CTAB}$ is also present along with the strontium ion. As is evident from potential vs log concentration plot of treated membrane [Fig. I(b)] it behaves as a better sensor for strontium ions and has larger validity range $\left(10^{-1}\right.$ to $\left.5 \times 10^{-5} \mathrm{M}\right)$. 
Table 2 Potential observed with strontium chloride and surfactant mixtures

\begin{tabular}{llllll}
\hline $\begin{array}{l}\text { Conc. of } \\
\text { strontium } \\
\text { ions } \\
(\mathrm{M})\end{array}$ & $\begin{array}{l}\text { Potential (mV) } \\
\text { from calibration } \\
\text { plot }\end{array}$ & $\begin{array}{l}\text { Potential (mV) when surfactant is also } \\
\text { present along with strontium ions }\end{array}$ \\
\hline $10^{-2}$ & -32.1 & -34.6 & -33.3 & -32.0 & -32.0 \\
$10^{-3}$ & -64.0 & -69.2 & -66.5 & -64.0 & -64.2 \\
$10^{-4}$ & -94.0 & -104.3 & -101.0 & -94.4 & -94.3 \\
\hline
\end{tabular}

The electrode has also been used as an end point indicator in potentiometric titration involving strontium ions. The titration of strontium chloride $\left(30 \mathrm{ml}, 10^{-2} \mathrm{M}\right)$ was performed with ammonium hydrogen phosphate $(0.1 \mathrm{M})$ and the same has been shown in Fig. 3. The break in the curve is satisfactorily sharp and probably represents a stoichiometric end point.

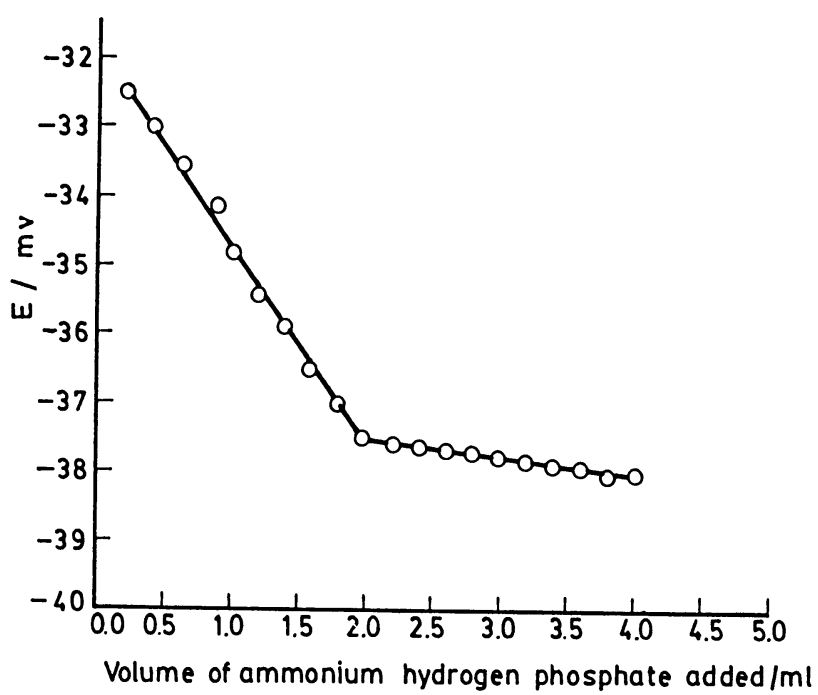

Fig. 3 Titration curve of strontium chloride with ammonium hydrogen phosphate

One of the authors (C.K.J.) is grateful to Council of Scientific and Industrial Research, India for financing this research project. 


\section{REFERENCES}

1) R.J. Levins : Anal. Chem., 43, 1045 (1971).

2) R.J. Levins : Anal.Chem., 44, 1544 (1972).

3) E.A. Materova,V.V. Muzhovikov : Electrokhimiya, I, 1741 (1971).

4) E.W. Baumann : Anal. Chem., 47, 959 (1975).

5) W.U. Malik, S.K. Srivastava, A. Bansal : Anal. Chem., 54, 1399 (1982).

6) S.K. Srivastava, A.K. Jain, S. Agarwal, R.P. Singh : Talanta, 25, 680 (1970).

7) S.K. Srivastava, A.K. Sharma, C.K. Jain : Talanta, 30, 285 (1983).

8) S.K. Srivastava, S. Kumar, C.K. Jain : The Analyst, 109, 667 (1984).

9) G॰H. Nancollas, R. Paterson : J. Inorg• Nucl. Chem•, 22, 253 (1961).

10) G.G. Guilbault : Ion Selective Electrode Review, 1, 139 (1979).

Keyword phrases

ion selective electrode; membrane electrode for strontium ions. 